\title{
Incidence, Characteristics and Outcomes of Delirium in Patients With Noninvasive Ventilation: A Prospective Observational Study
}

\section{Rui Zhang}

the First Affiliated Hospital of Chongqing Medical University

\section{Linfu Bai}

the First Affiliated Hospital of Chongqing Medical University

\section{Xiaoli Han}

the First Affiliated Hospital of Chongqing Medical University

Shicong Huang

the First Affiliated Hospital of Chongqing Medical Universithy

\section{Lintong Zhou}

the First Affiliated Hospital of Chongqing Medical University

Jun Duan ( $\nabla$ duanjun412589@163.com )

the First Affiliated Hospital of Chongqing Medical University https://orcid.org/0000-0003-1685-0117

Research article

Keywords: Delirium, Noninvasive ventilation, Risk factor

Posted Date: August 27th, 2020

DOI: https://doi.org/10.21203/rs.3.rs-60456/v1

License: (c) (i) This work is licensed under a Creative Commons Attribution 4.0 International License.

Read Full License 


\section{Abstract}

Background: Knowledge of delirium in noninvasive ventilation (NIV) is lacking. We aimed to report the incidence, characteristics and outcomes of delirium in NIV patients.

Methods: A prospective observational study was performed in an intensive care unit (ICU) of a teaching hospital. Patients who used NIV as a fist-line intervention were enrolled. During NIV intervention, delirium was screened using Confusion Assessment Method for the ICU every day.

Results: We enrolled 1083 patients. Of them, 196 patients (18.1\%) experienced delirium during NIV intervention. Patients with delirium had higher NIV failure rates (37.8\% vs. $21.0 \%, \mathrm{p} \otimes 0.01)$, higher ICU mortality (33.2\% vs. $14.3 \%, \mathrm{p} \otimes 0.01)$ and higher hospital mortality ( $37.2 \%$ vs. $17.0 \%, \mathrm{p} \otimes 0.01)$ than the subjects without delirium. They also spent longer time on NIV (median 6.3 vs. 3.7 days, $p \vee 0.01$ ), and stayed longer in ICU (median 9.0 vs. 6.0 days, $p \otimes 0.01$ ) and hospital (median 14.5 vs. 11.0 days, $p \otimes 0.01$ ). Furthermore, delirium was independently associated with NIV failure, ICU mortality and hospital mortality $(O R=1.97,2.58$ and 2.55 , respectively; all $p$ values $₫ 0.01)$. These results were confirmed in COPD and nonCOPD cohorts. Compared with hyperactive delirium patients, the NIV days was longer in hypoactive delirium patients and much longer in mixed delirium patients (median 3.4 vs. 6.5 vs. 10.1 days, $p \otimes 0.01$ ). Similar outcomes were found in the length of stay in ICU and hospital. However, the NIV failure, ICU mortality and hospital mortality did not differ between three subtypes of delirium.

Conclusions: Delirium increases the NIV failure rates, elevates the ICU and hospital mortality, prolongs the NIV days, and lengthens the ICU and hospital stay. Mixed delirium patients use more ICU resources than hypoactive delirium patients and much more than hyperactive delirium patients.

\section{Background}

Delirium is a manifestation characterized by the acute onset of cerebral dysfunction with a change or fluctuation in baseline mental status, inattention, and either disorganized thinking or an altered level of consciousness [1]. Hyperactive, hypoactive and mixed types of delirium are the three subtypes [2]. It frequently occurs in critically ill patients due to various reasons such as pain, stress, anxiety, sleep deprivation, sedation, analgesia and antimicrobial exposure [3-7]. A systematic review and meta-analysis has reported that the pooled incidence of delirium is $31.8 \%$ in critically ill patients [8]. And it is much higher (up to $80 \%$ ) in mechanically ventilated patients [9]. Delirium prolonged the length of stay (LOS) in ICU and hospital, increased hospital mortality and elevated hospital costs [8, 10-12]. Many strategies to prevent delirium have been widely investigated [13-15]. However, these studies mainly focused on mechanically ventilated or surgical patients. The knowledge on delirium in patients who received noninvasive ventilation (NIV) is lacking.

The aim of this study was to describe the incidence, clinical characteristics and outcomes of delirium in NIV patients, and further investigate the distribution of delirium in different subtypes. We also aimed to explore the association between delirium and NIV failure. 


\section{Methods}

This was a prospective observational study performed in an intensive care unit (ICU) of a teaching hospital from 2016 to 2018. The study protocol was approved by local institutional review board. As the observational nature of this study, the informed consent was waived. Patients who admitted to ICU for NIV as a first-line intervention were enrolled. However, patients less than 18 years old were excluded.

NIV (BiPAP Vision or V60; Philips Respironics, Carlsbad, CA) was initiated by the attending physicians based on the indications described previously $[16,17]$. In patients with chronic obstructive pulmonary disease (COPD), the indications for NIV were respiratory rate more than 25 breaths $/ \mathrm{min}, \mathrm{PaCO}_{2}$ more than $45 \mathrm{mmHg}$, pH less than $7.35, \mathrm{PaO}_{2} / \mathrm{FiO}_{2}$ less than $200 \mathrm{mmHg}$, and vigorous activity of accessory respiratory muscles. In patients with hypoxemic respiratory failure, the indications for NIV were clinical presentation of respiratory distress at rest (such as active contraction of the accessory inspiratory muscles or paradoxical abdominal motion), and $\mathrm{PaO}_{2} / \mathrm{FiO}_{2}$ less than $300 \mathrm{mmHg}$.

Face mask (ZS-MZ-A Face Mask, Shanghai Zhongshan Medical Technology Co., Shanghai, China) was the first choice to connect the patient and the ventilator. The size of the mask was fitted to the patients' face type. The S/T mode was used in COPD patients or other patients with labored breathing. The initial inspiratory positive airway pressure was $8-10 \mathrm{cmH}_{2} \mathrm{O}$ and then it was gradually increased to reach the tidal volume of $6-8 \mathrm{ml} / \mathrm{kg}$ or the maximal tolerated level. The initial expiratory positive airway pressure was $4 \mathrm{cmH}_{2} \mathrm{O}$. And then we gradually increased to counterbalance intrinsic positive end expiratory pressure in COPD patients. In hypoxemic respiratory failure patients, it was increased to maintain the alveoli patency and elevate the end expiratory lung volume. In patients with heart failure, the continuous positive airway pressure was used. The fractional concentration of oxygen was set to achieve peripheral oxygen saturation of $>92 \%$.

At the beginning of treatment, continuous use of NIV was encouraged. Once the patient recovered from respiratory failure, liberation from NIV was considered according to our hospital protocols [18]. However, the intubation was indicated if the respiratory failure progressively deteriorated. The criteria of intubation were listed as follows: respiratory or cardiac arrest, failure to maintain $\mathrm{PaO}_{2} / \mathrm{FiO}_{2}$ more than 100 , development of conditions necessitating intubation to protect the airway (coma or seizure disorders) or to manage copious tracheal secretions, inability to correct dyspnea, lack of improvement of signs of respiratory muscle fatigue, and hemodynamic instability without response to fluids and vasoactive agents $[16,17]$. NIV failure was defined as requirement of intubation.

Delirium was screened using Confusion Assessment Method for the ICU (CAM-ICU) every day [9]. The delirium was assessed based on the following 4 features: (1) fluctuation in mental status, (2) inattention, (3) disorganized thinking, and (4) altered levels of consciousness. Delirium was diagnosed in the presence of features 1 and 2 and either feature 3 or 4 . The level of consciousness was assessed by Richmond Agitation-Sedation Scale (RASS) [19]. RASS is a 10-point scale ranging from unarousable (- 5 points) or calm (0 points) to combative (4 points). Three subtypes of delirium were defined as follows 
[20]. Hyperactive delirium was defined as present in patients with all positive daily RASS scores (range, 1-4 points) associated with every positive CAM-ICU assessment. Hypoactive delirium was defined as present in patients with all neutral or negative daily RASS scores (range, 0 to -3 points) associated with every positive CAM-ICU assessment. Mixed delirium was defined as present in patients with daily RASS scores that included both positive values (range, 1-4 points) and neutral or negative values (range, 0 to 3 points) associated with every positive CAM-ICU assessment.

\section{Statistical analysis}

Statistical software (SPSS 17.0; IBM Corp., Armonk, NY) was used to analyze the data. Continuous variables were presented as means with standard deviations or medians and interquartiles $(25-75 \%)$ when appropriate. Differences between groups were analyzed using Student's t test or Mann-Whitney U test as appropriate. Categorical variables were reported as frequencies and percentages. Differences between groups were analyzed using Chi-squared test or Fisher's exact test. Multivariate logistic regression analysis was used to identify the independent risk factors associated with NIV failure, ICU mortality and hospital mortality. The probability of patients remaining on NIV and in the ICU was analyzed using Kaplan-Meier curves (log-rank test). Statistical significance was considered if a $p$ value was less than 0.05 .

\section{Results}

We enrolled 1083 patients in this study. Of these, 196 (18.1\%) developed delirium during NIV intervention. There were no differences on reasons for NIV, underlying disease, sex, heart rate, respiratory rate, $\mathrm{PaCO}_{2}$ and $\mathrm{PaO}_{2} / \mathrm{FiO}_{2}$ between patients with and without delirium (Table 1 ). However, delirious patients were older than non-delirious ones. They also had higher APACHE II score, lower Glasgow coma scale (GCS), lower mean arterial pressure, and lower $\mathrm{pH}$. Furthermore, delirious patients had higher NIV failure rates, higher ICU mortality, and higher hospital mortality than non-delirious patients. They also spent longer time on NIV and stayed longer in ICU and hospital than non-delirious patients (Supplementary Fig. 1). 
Table 1

Comparisons in patients with and without delirium

\begin{tabular}{|c|c|c|c|}
\hline \multirow[t]{2}{*}{ Variables } & No delirium & Delirium & \multirow[t]{2}{*}{$p$} \\
\hline & $N=887$ & $N=196$ & \\
\hline Age, years & $67 \pm 14$ & $77 \pm 11$ & $\varangle 0.01$ \\
\hline Female/Male & $261 / 626$ & $49 / 147$ & 0.22 \\
\hline APACHE II score & $15 \pm 4$ & $17 \pm 4$ & $\nabla 0.01$ \\
\hline \multicolumn{4}{|l|}{ Reasons for NIV } \\
\hline COPD exacerbation & $477(53.8 \%)$ & $107(54.6 \%)$ & \multirow[t]{10}{*}{0.67} \\
\hline Pneumonia & $184(20.7 \%)$ & $48(24.5 \%)$ & \\
\hline ARDS & $63(7.1 \%)$ & $11(5.6 \%)$ & \\
\hline Pulmonary cancer & $49(5.5 \%)$ & $11(5.6 \%)$ & \\
\hline Interstitial lung disease & $22(2.5 \%)$ & $6(3.1 \%)$ & \\
\hline Asthma & $14(1.6 \%)$ & $1(0.5 \%)$ & \\
\hline Heart failure & $10(1.1 \%)$ & $2(1.0 \%)$ & \\
\hline $\mathrm{OHS}$ & $11(1.2 \%)$ & $2(1.0 \%)$ & \\
\hline Pulmonary embolism & $15(1.7 \%)$ & $0(0 \%)$ & \\
\hline Others & $42(4.7 \%)$ & $8(4.1 \%)$ & \\
\hline \multicolumn{4}{|l|}{ Underlying disease } \\
\hline Hypertension & $335(37.8 \%)$ & $86(43.9 \%)$ & 0.12 \\
\hline Diabetes mellitus & $180(20.3 \%)$ & $51(26.0 \%)$ & 0.08 \\
\hline Chronic heart disease & $163(18.4 \%)$ & $47(24.0 \%)$ & 0.09 \\
\hline Chronic liver disease & $36(4.1 \%)$ & $4(2.0 \%)$ & 0.21 \\
\hline Chronic kidney disease & $30(3.4 \%)$ & $11(5.6 \%)$ & 0.15 \\
\hline \multicolumn{4}{|c|}{ Variables collected before NIV } \\
\hline GCS & $14.8 \pm 0.8$ & $14.1 \pm 1.6$ & $\varangle 0.01$ \\
\hline $\mathrm{HR}$, beats/min & $111 \pm 23$ & $112 \pm 22$ & 0.92 \\
\hline $\mathrm{RR}$, breaths/min & $31 \pm 7$ & $31 \pm 7$ & 0.73 \\
\hline $\begin{array}{l}\text { NIV = noninvasive ventil } \\
\text { respiratory disease synd } \\
\mathrm{HR}=\text { heart rate, } \mathrm{RR}=\text { res }\end{array}$ & $\begin{array}{l}\text { ic obstructive } \\
\text { y hypoventila } \\
\text { mean arteria }\end{array}$ & $\begin{array}{l}\text { disease, ARL } \\
\text { me, GCS = Gla } \\
\text { OS = length o }\end{array}$ & scale, \\
\hline
\end{tabular}




\begin{tabular}{|c|c|c|c|}
\hline \multirow[t]{2}{*}{ Variables } & No delirium & Delirium & \multirow[t]{2}{*}{$p$} \\
\hline & $N=887$ & $N=196$ & \\
\hline MAP, mmHg & $100 \pm 18$ & $95 \pm 17$ & $\nabla 0.01$ \\
\hline $\mathrm{pH}$ & $7.37 \pm 0.10$ & $7.34 \pm 0.11$ & $\varangle 0.01$ \\
\hline $\mathrm{PaCO}_{2}, \mathrm{mmHg}$ & $58 \pm 25$ & $61 \pm 27$ & 0.16 \\
\hline $\mathrm{PaO}_{2} / \mathrm{FiO}_{2}, \mathrm{mmHg}$ & $184 \pm 87$ & $190 \pm 92$ & 0.45 \\
\hline \multicolumn{4}{|l|}{ Outcomes } \\
\hline NIV failure & $186(21.0 \%)$ & 74 (37.8\%) & $\varangle 0.01$ \\
\hline NIV duration, days & $3.7(1.7-5.9)$ & $6.3(2.7-11.0)$ & $\nabla 0.01$ \\
\hline ICU LOS, days & $6.0(3.8-9.2)$ & $9.0(4.8-15.2)$ & $\bowtie 0.01$ \\
\hline Hospital LOS, days & $11.0(6.8-17.0)$ & $14.5(7.1-21.1)$ & $\otimes 0.01$ \\
\hline ICU mortality & $127(14.3 \%)$ & $65(33.2 \%)$ & $\otimes 0.01$ \\
\hline Hospital mortality & $151(17.0 \%)$ & $73(37.2 \%)$ & $\varangle 0.01$ \\
\hline \multicolumn{4}{|c|}{$\begin{array}{l}\text { NIV = noninvasive ventilation, } \mathrm{COPD}=\text { chronic obstructive pulmonary disease, ARDS = acute } \\
\text { respiratory disease syndrome, OHS = obesity hypoventilation syndrome, GCS = Glasgow coma scale } \\
\mathrm{HR}=\text { heart rate, } \mathrm{RR}=\text { respiratory rate, MAP = mean arterial pressure, } \mathrm{LOS}=\text { length of stay }\end{array}$} \\
\hline
\end{tabular}

Delirium was independently associated with NIV failure (odds ratio $[\mathrm{OR}]=1.97,95 \%$ confidence interval $[\mathrm{Cl}]$ : 1.34-2.88), ICU mortality (OR $=2.58,95 \% \mathrm{Cl}: 1.74-3.84)$ and hospital mortality $(\mathrm{OR}=2.55,95 \% \mathrm{Cl}$ : 1.74-3.75) (Table 2). These results were confirmed in patients with and without COPD. 
Table 2

Multivariate analysis of risk factors for NIV failure, ICU mortality and hospital mortality

\begin{tabular}{|c|c|c|c|c|c|c|}
\hline Variables & Overall cohort & & COPD cohort & & $\begin{array}{l}\text { Non-COPD } \\
\text { cohort }\end{array}$ & \\
\hline & OR $(95 \% \mathrm{Cl})$ & $p$ & OR $(95 \% \mathrm{Cl})$ & $p$ & OR $(95 \% \mathrm{Cl})$ & $p$ \\
\hline \multicolumn{7}{|c|}{ Risk factors for NIV failure } \\
\hline Delirium & $1.97(1.34-2.88)$ & $\varangle 0.01$ & $\begin{array}{l}2.33(1.27- \\
4.30)\end{array}$ & $\otimes 0.01$ & $1.84(1.13-2.99)$ & 0.02 \\
\hline $\begin{array}{l}\text { APACHE II } \\
\text { score }\end{array}$ & $1.08(1.03-1.12)$ & $\nabla 0.01$ & $\begin{array}{l}1.09(1.02- \\
1.17)\end{array}$ & 0.02 & $1.10(1.05-1.15)$ & $\varangle 0.01$ \\
\hline GCS & $0.78(0.66-0.91)$ & $\nabla 0.01$ & - & - & - & - \\
\hline $\begin{array}{l}\mathrm{RR}, \\
\text { breaths/min }\end{array}$ & $1.03(1.00-1.05)$ & 0.02 & - & - & - & - \\
\hline $\mathrm{PaCO}_{2}, \mathrm{mmHg}$ & $\begin{array}{l}0.975(0.968- \\
0.982)\end{array}$ & $\nabla 0.01$ & - & - & - & - \\
\hline $\begin{array}{l}\mathrm{PaO}_{2} / \mathrm{FiO}_{2} \\
\mathrm{mmHg}\end{array}$ & $\begin{array}{l}0.996(0.993- \\
0.998)\end{array}$ & $\nabla 0.01$ & - & - & $\begin{array}{l}0.995(0.992- \\
0.998)\end{array}$ & 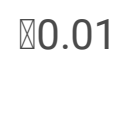 \\
\hline Age, years & - & - & $\begin{array}{l}1.04(1.01- \\
1.08)\end{array}$ & $₫ 0.01$ & - & - \\
\hline $\mathrm{HR}$, beats/min & - & - & $\begin{array}{l}1.01(1.00- \\
1.03)\end{array}$ & 0.04 & - & - \\
\hline $\begin{array}{l}\text { Diabetes } \\
\text { mellitus }\end{array}$ & - & - & - & - & $0.57(0.36-0.91)$ & 0.02 \\
\hline \multicolumn{7}{|c|}{ Risk factors for ICU mortality } \\
\hline Delirium & $2.58(1.74-3.84)$ & $\nabla 0.01$ & $\begin{array}{l}3.64(1.89- \\
7.01)\end{array}$ & $\triangle 0.01$ & $2.16(1.31-3.56)$ & $\mathbb{\nabla} 0.01$ \\
\hline $\begin{array}{l}\text { APACHE II } \\
\text { score }\end{array}$ & $1.06(1.01-1.11)$ & 0.01 & $\begin{array}{l}1.18(1.09- \\
1.28)\end{array}$ & $₫ 0.01$ & $1.06(1.01-1.11)$ & 0.03 \\
\hline GCS & $0.77(0.65-0.91)$ & $\nabla 0.01$ & - & - & - & - \\
\hline $\begin{array}{l}\text { RR, } \\
\text { breaths/min }\end{array}$ & $1.04(1.01-1.06)$ & $\triangle 0.01$ & - & - & $1.03(1.00-1.06)$ & 0.03 \\
\hline
\end{tabular}

$\mathrm{NIV}=$ noninvasive ventilation, $\mathrm{OR}=$ odds ratio, $\mathrm{Cl}=$ confidence internal, $\mathrm{GCS}=$ Glasgow coma scale, $\mathrm{HR}=$ heart rate, $\mathrm{RR}=$ respiratory rate, $\mathrm{COPD}=$ chronic obstructive pulmonary disease

Delirium, sex, age, underlying disease, APACHE II score, GCS, heart rate, respiratory rate, $\mathrm{pH}, \mathrm{PaCO}_{2}$ and $\mathrm{PaO}_{2} / \mathrm{FiO}_{2}$ were entered into multivariate analysis to identify independent risk factors for NIV failure, ICU mortality and hospital mortality, respectively. 


\begin{tabular}{|c|c|c|c|c|c|c|}
\hline Variables & Overall cohort & & COPD cohort & & $\begin{array}{l}\text { Non-COPD } \\
\text { cohort }\end{array}$ & \\
\hline $\mathrm{PaCO}_{2}, \mathrm{mmHg}$ & $\begin{array}{l}0.978(0.970- \\
0.985)\end{array}$ & $₫ 0.01$ & - & - & - & - \\
\hline $\mathrm{PaO}_{2} / \mathrm{FiO}_{2}$ & $\begin{array}{l}0.998(0.995- \\
1.000)\end{array}$ & 0.04 & - & - & $\begin{array}{l}0.997(0.994- \\
1.000)\end{array}$ & 0.04 \\
\hline Age, years & - & - & $\begin{array}{l}1.04(1.01- \\
1.08)\end{array}$ & 0.03 & - & - \\
\hline \multicolumn{7}{|c|}{ Risk factors for hospital mortality } \\
\hline Delirium & $2.55(1.74-3.75)$ & $\nabla 0.01$ & $\begin{array}{l}3.34(1.81- \\
6.18)\end{array}$ & $\otimes 0.01$ & $2.11(1.29-3.45)$ & $\varangle 0.01$ \\
\hline $\begin{array}{l}\text { APACHE II } \\
\text { score }\end{array}$ & $1.08(1.03-1.13)$ & $\nabla 0.01$ & $\begin{array}{l}1.09(1.02- \\
1.17)\end{array}$ & 0.02 & $1.09(1.04-1.14)$ & $\bigotimes 0.01$ \\
\hline $\mathrm{HR}$, beats/min & $1.01(1.00-1.02)$ & 0.05 & $\begin{array}{l}1.02(1.00- \\
1.03)\end{array}$ & 0.01 & - & - \\
\hline $\begin{array}{l}\text { RR, } \\
\text { breaths/min }\end{array}$ & $1.03(1.00-1.05)$ & 0.03 & - & - & $1.03(1.00-1.06)$ & 0.02 \\
\hline GCS & $0.82(0.67-0.97)$ & 0.02 & - & - & - & - \\
\hline $\mathrm{PaCO}_{2}, \mathrm{mmHg}$ & $\begin{array}{l}0.975(0.968- \\
0.983)\end{array}$ & $\nabla 0.01$ & - & - & - & - \\
\hline $\mathrm{PaO}_{2} / \mathrm{FiO}_{2}$ & - & - & - & - & $\begin{array}{l}0.997(0.995- \\
1.000)\end{array}$ & 0.05 \\
\hline Age, years & - & - & $\begin{array}{l}1.06(1.03- \\
1.10)\end{array}$ & $\nabla 0.01$ & - & - \\
\hline \multicolumn{7}{|c|}{$\begin{array}{l}\mathrm{NIV}=\text { noninvasive ventilation, } \mathrm{OR}=\text { odds ratio, } \mathrm{Cl}=\text { confidence internal, } \mathrm{GCS}=\text { Glasgow coma scale, } \\
\mathrm{HR}=\text { heart rate, } \mathrm{RR}=\text { respiratory rate, } \mathrm{COPD}=\text { chronic obstructive pulmonary disease }\end{array}$} \\
\hline \multicolumn{7}{|c|}{$\begin{array}{l}\text { Delirium, sex, age, underlying disease, APACHE II score, } \mathrm{GCS} \text {, heart rate, respiratory rate, } \mathrm{pH}, \mathrm{PaCO}_{2} \\
\text { and } \mathrm{PaO}_{2} / \mathrm{FiO}_{2} \text { were entered into multivariate analysis to identify independent risk factors for NIV } \\
\text { failure, ICU mortality and hospital mortality, respectively. }\end{array}$} \\
\hline
\end{tabular}

Among the delirious patients, 51 (26\%) developed hyperactive delirium, 123 (63\%) developed hypoactive delirium, and 22 (11\%) developed mixed delirium (Table 3). There were no differences in NIV failure, ICU and hospital mortality between three groups. Patients with hyperactive delirium had lowest NIV duration, ICU stay and hospital stay. However, it was higher in patients with hypoactive delirium and much higher in those with mixed delirium (Table 3 and Fig. 1). 
Table 3

Subgroup analysis in patients with different subtypes of delirium

\begin{tabular}{|c|c|c|c|c|}
\hline Variables & $\begin{array}{l}\text { Hyperactive delirium } \\
\mathrm{N}=51\end{array}$ & $\begin{array}{l}\text { Hypoactive delirium } \\
N=123\end{array}$ & $\begin{array}{l}\text { Mixed delirium } \\
N=22\end{array}$ & $\mathbf{P}$ \\
\hline NIV failure & 19 (37.3\%) & $47(38.2 \%)$ & $8(36.4 \%)$ & 0.98 \\
\hline ICU mortality & $16(31.4 \%)$ & $41(33.3 \%)$ & $8(36.4 \%)$ & 0.92 \\
\hline Hospital mortality & $17(33.3 \%)$ & $47(38.2 \%)$ & $9(40.9 \%)$ & 0.78 \\
\hline NIV duration, days & $3.4(1.7-8.8)$ & $6.5(2.9-11.0)$ & $10.1(6.3-20.5)$ & $\otimes 0.01$ \\
\hline ICU LOS, days & $6.8(3.3-14.1)$ & $8.9(5.0-15.1)$ & $12.3(8.1-21.2)$ & $\varangle 0.01$ \\
\hline Hospital LOS, days & $12.9(5.8-19.0)$ & $15.0(7.9-21.0)$ & $19.5(9.5-31.0)$ & 0.03 \\
\hline Delirium days & $1(1-2)$ & $1(1-3)$ & $7(3-12)$ & $\varangle 0.01$ \\
\hline
\end{tabular}

Age $(\mathrm{OR}=1.06,95 \% \mathrm{Cl}: 1.04-1.08)$ and $\mathrm{APACHE}$ II score $(\mathrm{OR}=1.07,95 \% \mathrm{Cl}: 1.03-1.13)$ were risk factors for delirium, and GCS (OR $=0.67,95 \% \mathrm{Cl}: 0.56-0.79)$ and mean arterial pressure (OR $=0.99,95 \% \mathrm{Cl}$ : $0.98-$ 1.00) were protective factors (Table 4). However, in patients without COPD, only age and GCS were associated with delirium. The distribution of delirium in different ages and GCS scores were summarized in Fig. 2. Patients with age more than 75 years and GCS less than 14 had the highest incidence of delirium. 
Table 4

Multivariate analysis of risk factors for delirium

\begin{tabular}{|c|c|c|c|c|c|c|}
\hline Variables & Overall cohort & & COPD cohort & & $\begin{array}{l}\text { Non-COPD } \\
\text { cohort }\end{array}$ & \\
\hline & OR (95\%Cl) & $p$ & OR (95\%Cl) & $p$ & OR (95\%Cl) & $p$ \\
\hline Age, years & $\begin{array}{l}1.06(1.04- \\
1.08)\end{array}$ & $\bowtie 0.01$ & $\begin{array}{l}1.06(1.03- \\
1.09)\end{array}$ & $\nabla 0.01$ & $1.07(1.05-1.09)$ & $\otimes 0.01$ \\
\hline GCS & $\begin{array}{l}0.67(0.56- \\
0.79)\end{array}$ & $\nabla 0.01$ & $\begin{array}{l}0.74(0.60- \\
0.92)\end{array}$ & $\otimes 0.01$ & $0.48(0.37-0.63)$ & 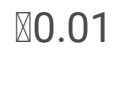 \\
\hline $\begin{array}{l}\text { APACHE II } \\
\text { score }\end{array}$ & $\begin{array}{l}1.07(1.03- \\
1.13)\end{array}$ & $\varangle 0.01$ & $1.08(1.00-1.15)$ & 0.04 & - & - \\
\hline MAP & $0.99(0.98-1.00)$ & 0.01 & $\begin{array}{l}0.98(0.97- \\
0.99)\end{array}$ & $\bowtie 0.01$ & - & - \\
\hline \multicolumn{7}{|c|}{$\begin{array}{l}\mathrm{NIV}=\text { noninvasive ventilation, } \mathrm{OR}=\text { odds ratio, } \mathrm{Cl}=\text { confidence internal, } \mathrm{GCS}=\mathrm{Glasgow} \text { coma scale, } \\
\mathrm{RR}=\text { respiratory rate, } \mathrm{MAP}=\text { mean arterial pressure, } \mathrm{COPD}=\text { chronic obstructive pulmonary disease }\end{array}$} \\
\hline \multicolumn{7}{|c|}{$\begin{array}{l}\text { Reasons for } \mathrm{NIV} \text {, sex, age, underlying disease, APACHE II score, GCS, heart rate, respiratory rate, } \mathrm{pH} \text {, } \\
\mathrm{PaCO}_{2} \text { and } \mathrm{PaO}_{2} / \mathrm{FiO}_{2} \text { were entered into to multivariate analysis to identify independent risk factors } \\
\text { for delirium. }\end{array}$} \\
\hline
\end{tabular}

\section{Discussion}

To the best of our knowledge, our study is the largest to explore the incidence, characteristics and outcomes of delirium in NIV patients. A systematic review and meta-analysis has enrolled 239 NIV patients who were assessed the incidence of delirium [21]. The data were extracted from three studies published before 2012 [22-24]. In Rozzini's study, it only enrolled COPD patients $₫ 65$ years old, and failed to report how the delirium was assessed [22]. And in Carlucci's study, the delirium was considered if the moderate or pronounced encephalopathy was diagnosed [23]. Only in Roche Campo's study, the delirium was assessed by CAM-ICU (a recommended tool for diagnosis of delirium), but it only enrolled hypercapnic patients with median age of 82 years old [24]. Therefore, the report of this systematic review is inaccurate. Another study was published at 2016 [25]. It enrolled 153 hypercapnic patients, and only reported the association between delirium and 1-year mortality. As the small sample size, no one reported the situation in different subtypes of delirium [21-25]. However, we enrolled 1083 NIV patients involving different age and diagnosis. The large sample size enabled us to perform stratification analysis based on diagnosis and age, and further explore the situations between patients with different subtypes of delirium.

Hypoactive delirium was the most common subtype reported by Krewulak et al. [2]. In Gual's study, hyperactive delirium was the most common subtype [26]. In our study, the hypoactive delirium was the major subtype, hyperactive delirium was in the middle, and mixed delirium was the lowest one. In addition, the patients with mixed delirium had the longest delirium days and ICU stays. To the best of our 
knowledge, this is the first study to report the distribution of subtypes of delirium in NIV patients. Therefore, it adds something new to the field to help the clinical practitioners to manage NIV patients.

Age, level of consciousness and disease severity were risk factors for delirium [27-29]. Our study also demonstrated this issue. However, different with previous studies, we found that mean arterial pressure was a protective factor for delirium. Patients with lower mean arterial pressure were more likely to experience delirium in NIV intervention. The low mean arterial pressure may decrease the cerebral blood flow perfusion and lead to neuropsychic symptom, and subsequently cause delirium. However, this is just a hypothesis, and further exploration is required.

Many studies have reported that disease severity, low level of consciousness, increased respiratory rate and decreased oxygenation were associated with NIV failure [30,31]. Our study also confirmed this issue. Different with previous studies, we found that delirium was independently associated with NIV failure both in patients with and without COPD. It provides a new insight to clinical practitioners to understand NIV failure.

Delirium was highly associated with ICU and hospital mortality $[8,10-12]$. Our study confirmed this point in NIV population. As poor prognosis in delirium patients, prevention of delirium was needed. Pain relief, early mobilization, improvement of sleep quality and minimized noise were the promising methods to reduce delirium in NIV patients [32].

This is a single center observational study performed in an ICU. As we only enrolled medical patients, the incidence of delirium may be skewed. In addition, we only enrolled patients who used NIV as a first-line intervention. Those who used NIV due to postextubation respiratory failure or prevention of extubation failure were excluded since the previous exposure in mechanical ventilation highly associated with delirium. So, the results in our study cannot be extrapolated to the patients who used NIV after extubation.

\section{Conclusions}

The incidence of delirium in NIV population is high. The hypoactive delirium is the most common subtype in this population. Delirium increases the NIV failure rates, elevates the ICU and hospital mortality, prolongs the NIV days, and lengthens the ICU and hospital stay.

\section{Abbreviations}

NIV = noninvasive ventilation; ICU = intensive care unit; COPD = chronic obstructive pulmonary disease; ARDS = acute respiratory distress syndrome; $\mathrm{OHS}$ = obesity hypoventilation syndrome; GCS = Glasgow coma scale; $\mathrm{HR}=$ heart rate; $\mathrm{RR}$ = respiratory rate; $\mathrm{MAP}=$ mean arterial pressure; $\mathrm{LOS}$ = length of stay; $\mathrm{OR}$ = odds ratio; $\mathrm{Cl}=$ confidence interval; $\mathrm{CAM}-\mathrm{ICU}=$ Confusion Assessment Method for the ICU; RASS = Richmond Agitation-Sedation Scale 


\section{Declarations}

\section{Consent for publication}

All authors have reviewed and approved the manuscript for publication.

\section{Availability of data and material}

The datasets analyzed during the current study available from the corresponding author on reasonable request.

\section{Ethical approval and consent to participate}

The Institutional Review Board of the First Affiliated Hospital of Chongqing Medical University approved the study protocol. Informed consent was waived as the observational nature.

\section{Competing interests}

We declare that we have no competing interests.

\section{Funding}

This study was supported by the National Natural Science Foundation of China (Grant No. 81700015) and by Cultivating Fund of the First Affiliated Hospital of Chongqing Medical University (Grant No. PYJJ2017-20)

\section{Authors' contributions}

JD conceived the study, joined in study design, study management, data collection, data analysis, and manuscript revision. RZ participated in study design, study management, data collection and drafted the manuscript. $\mathrm{LB}, \mathrm{XH}, \mathrm{SH}$ and $\mathrm{LZ}$ participated in study design and data collection, and revised the manuscript. All authors read and approved the final version.

\section{Acknowledgements}

We thank all the staffs in ICUs to participate in data collection.

\section{References}

1. Barr J, Fraser GL, Puntillo K, et al. Clinical practice guidelines for the management of pain, agitation, and delirium in adult patients in the intensive care unit. Crit Care Med 2013; 41:263-306.

2. Krewulak KD, Stelfox HT, Leigh JP, et al. Incidence and Prevalence of Delirium Subtypes in an Adult ICU: A Systematic Review and Meta-Analysis. Crit Care Med 2018; 46:2029-2035. 
3. Hayhurst CJ, Pandharipande PP, Hughes CG. Intensive Care Unit Delirium: A Review of Diagnosis, Prevention, and Treatment. Anesthesiology 2016; 125:1229-1241.

4. Pandharipande PP, Ely EW, Arora RC, et al. The intensive care delirium research agenda: a multinational, interprofessional perspective. Intensive Care Med 2017; 43:1329-1339.

5. Knauert MP, Gilmore EJ, Murphy TE, et al. Association between death and loss of stage N2 sleep features among critically III patients with delirium. J Crit Care 2018; 48:124-129.

6. Devlin JW, Skrobik Y, Gelinas C, et al. Clinical Practice Guidelines for the Prevention and Management of Pain, Agitation/Sedation, Delirium, Immobility, and Sleep Disruption in Adult Patients in the ICU. Crit Care Med 2018; 46:e825-e873.

7. Grahl JJ, Stollings JL, Rakhit S, et al. Antimicrobial exposure and the risk of delirium in critically ill patients. Crit Care 2018; 22:337.

8. Salluh JI, Wang H, Schneider EB, et al. Outcome of delirium in critically ill patients: systematic review and meta-analysis. BMJ 2015; 350:h2538.

9. Ely EW, Inouye SK, Bernard GR, et al. Delirium in mechanically ventilated patients: validity and reliability of the confusion assessment method for the intensive care unit (CAM-ICU). JAMA 2001; 286:2703-2710.

10. Kim S, Kim JJ, Oh J, et al. Delirium characteristics and outcomes in medical and surgical Inpatients: A subgroup analysis. J Crit Care 2018; 43:156-162.

11. Shehabi Y, Riker RR, Bokesch PM, et al. Delirium duration and mortality in lightly sedated, mechanically ventilated intensive care patients. Crit Care Med 2010; 38:2311-2318.

12. Milbrandt EB, Deppen $\mathrm{S}$, Harrison PL, et al. Costs associated with delirium in mechanically ventilated patients. Crit Care Med 2004; 32:955-962.

13. Su X, Meng ZT, Wu XH, et al. Dexmedetomidine for prevention of delirium in elderly patients after non-cardiac surgery: a randomised, double-blind, placebo-controlled trial. Lancet 2016; 388:18931902.

14. van den Boogaard M, Slooter AJC, Bruggemann RJM, et al. Effect of Haloperidol on Survival Among Critically III Adults With a High Risk of Delirium: The REDUCE Randomized Clinical Trial. JAMA 2018; 319:680-690.

15. Skrobik Y, Duprey MS, Hill NS, et al. Low-Dose Nocturnal Dexmedetomidine Prevents ICU Delirium. A Randomized, Placebo-controlled Trial. Am J Respir Crit Care Med 2018; 197:1147-1156.

16. Fan L, Zhao Q, Liu Y, et al. Semiquantitative cough strength score and associated outcomes in noninvasive positive pressure ventilation patients with acute exacerbation of chronic obstructive pulmonary disease. Respir Med 2014; 108:1801-1807.

17. Duan J, Han X, Bai L, et al. Assessment of heart rate, acidosis, consciousness, oxygenation, and respiratory rate to predict noninvasive ventilation failure in hypoxemic patients. Intensive Care Med 2017; 43:192-199. 
18. Duan J, Tang X, Huang S, et al. Protocol-directed versus physician-directed weaning from noninvasive ventilation: the impact in chronic obstructive pulmonary disease patients. J Trauma Acute Care Surg 2012; 72:1271-1275.

19. Sessler CN, Gosnell MS, Grap MJ, et al. The Richmond Agitation-Sedation Scale: validity and reliability in adult intensive care unit patients. Am J Respir Crit Care Med 2002; 166:1338-1344.

20. Robinson TN, Raeburn CD, Tran ZV, et al. Motor subtypes of postoperative delirium in older adults. Arch Surg 2011; 146:295-300.

21. Charlesworth M, Elliott MW, Holmes JD. Noninvasive positive pressure ventilation for acute respiratory failure in delirious patients: understudied, underreported, or underappreciated? A systematic review and meta-analysis. Lung 2012; 190:597-603.

22. Rozzini R, Sabatini T, Trabucchi M. Non-invasive ventilation for respiratory failure in elderly patients. Age Ageing 2006; 35:546-547.

23. Carlucci A, Richard JC, Wysocki M, et al. Noninvasive versus conventional mechanical ventilation. An epidemiologic survey. Am J Respir Crit Care Med 2001; 163:874-880.

24. Roche Campo F, Drouot $X$, Thille AW, et al. Poor sleep quality is associated with late noninvasive ventilation failure in patients with acute hypercapnic respiratory failure. Crit Care Med 2010; 38:477485 .

25. Chan KY, Cheng LS, Mak IW, et al. Delirium is a Strong Predictor of Mortality in Patients Receiving Non-invasive Positive Pressure Ventilation. Lung 2017; 195:115-125.

26. Gual N, Inzitari M, Carrizo G, et al. Delirium Subtypes and Associated Characteristics in Older Patients With Exacerbation of Chronic Conditions. Am J Geriatr Psychiatry 2018; 26:1204-1212.

27. Janssen TL, Hosseinzoi E, Vos DI, et al. The importance of increased awareness for delirium in elderly patients with rib fractures after blunt chest wall trauma: a retrospective cohort study on risk factors and outcomes. BMC Emerg Med 2019; 19:34.

28. Gual N, Morandi A, Perez LM, et al. Risk Factors and Outcomes of Delirium in Older Patients Admitted to Postacute Care with and without Dementia. Dement Geriatr Cogn Disord 2018; 45:121-129.

29. Chaiwat $O$, Chanidnuan $M$, Pancharoen $W$, et al. Postoperative delirium in critically ill surgical patients: incidence, risk factors, and predictive scores. BMC Anesthesiol 2019; 19:39.

30. Ozyilmaz E, Ugurlu AO, Nava S. Timing of noninvasive ventilation failure: causes, risk factors, and potential remedies. BMC Pulm Med 2014; 14:19.

31. Nava S, Hill N. Non-invasive ventilation in acute respiratory failure. Lancet 2009; 374:250-259.

32. Tang B, Wang XT, Chen WJ, et al. [Experts consensus on the management of delirium in critically ill patients]. Zhonghua Nei Ke Za Zhi 2019; 58:108-118.

\section{Figures}



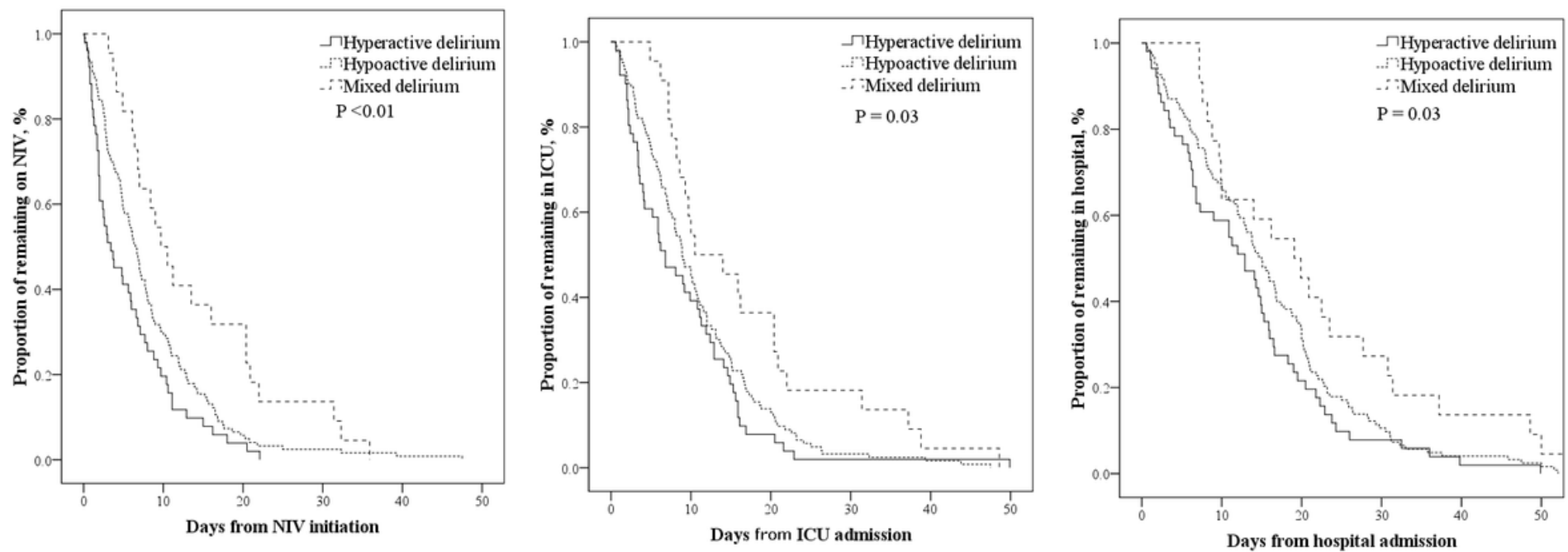

Figure 1

Resources use among patients with hyperactive, hypoactive and mixed delirium.

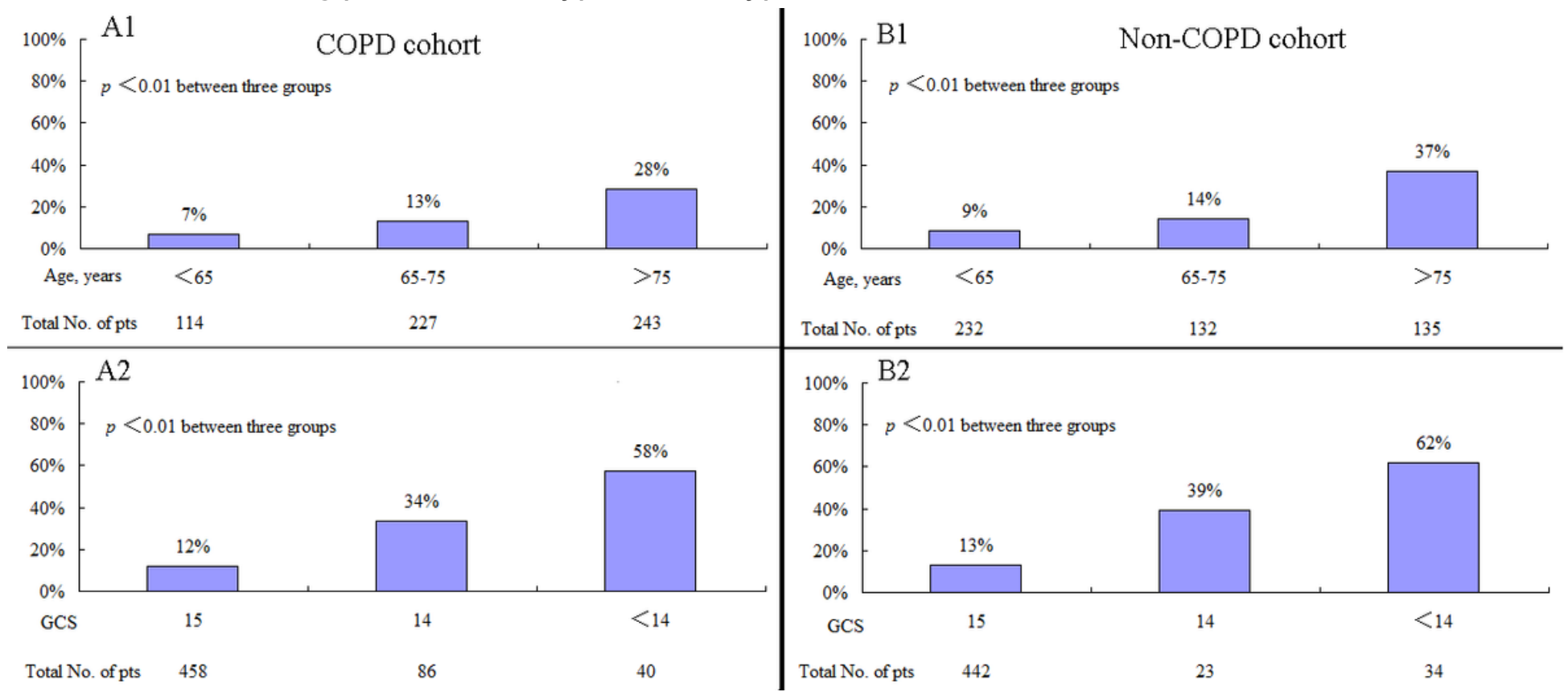

Figure 2

Distributions of delirium in patients with different age and GCS. A1 and A2 indicate the COPD cohort. B1 and B2 indicate the non-COPD cohort.

\section{Supplementary Files}

This is a list of supplementary files associated with this preprint. Click to download.

- Supplementaryfigure1.tif 